\title{
Applied Transdérmic Photobiomodulator Therapy About the Primary Carotide Artery in Patients Under Hormonal Blockers and Dynude Disorders and Pathogenic Flora of Orofaringeo and Systemic Repercussions
}

\author{
Juliano Abreu Pacheco'* ${ }^{1 *}$ Adriana Schapochnik ${ }^{2}$, Cláudia Conforto de Sá ${ }^{3}$, Antônio Cesar M \\ Santiago ${ }^{4}$, Guilherme Luna Martinez ${ }^{5}$ and Marco Aurelio Kenichi Yamaji ${ }^{6}$ \\ ${ }^{1}$ Dental surgeon, Coordinator of Research of the Ribeirão Preto Cancer Hospital, Brazil
}

${ }^{2}$ Physiotherapist, Specialist in traditional Chinese medicine, Brazil

${ }^{3}$ Physiotherapist, Pedagogical Coordinator of ISPA, Brazil

${ }^{4}$ Oncologist Ribeirao Preto Cancer Hospital, Brazil

${ }^{5}$ Department of Gynecology and Obstetrics, Mauá University in Breast Ultrasound, Brazil

${ }^{6}$ Housing in Oral and Maxillofacial Surgery, Brazil

*Corresponding author: Juliano Abreu Pacheco, Dental surgeon, Coordinator of Research of the Ribeirão Preto Cancer Hospital, Enabled in Hospital Dentistry Hospital Israelista Albert Einstein, Master in Intensive Care at Imbes-SP, Professor of Dental Care Broadcasting Course in Oncology Patients-FORP / USP, Brazil.

To Cite This Article: Juliano Abreu Pacheco. Applied Transdérmic Photobiomodulator Therapy About the Primary Carotide Artery in Patients Under Hormonal Blockers and Dynude Disorders and Pathogenic Flora of Orofaringeo and Systemic Repercussions. Am J Biomed Sci \& Res. 2019 - 4(4). AJBSR.MS.ID.000813. DOI: 10.34297/AJBSR.2019.04.000813

Received: July 03, 2019 | Published: August 08, 2019

\begin{abstract}
The purpose of this study is to categorize a transdermal anatomical location in the Primitive Carotid Artery (Common) for the use of modified Intrasvacular LASER Irradiation of Blood (ILIB). This study was conducted in twelve patients undergoing hormone blockers - Anastrozole / six and Tamoxifen / six and five patients without hormone therapy, all of which were performed in patients currently undergoing disease control therapy, where the site primary neoplastic were the mammary ducts (uni or bilateral). The noninvasive therapy of systemic LASER in the cervical region was motivated by the biological, technical and functional inactivity guided by the INCA (National Cancer Institute - Brazil) in order to avoid any manipulations on the same side of the operated breast, specifically the arm, due to to the possibilities of undesirable intercurrences that may cause clinical lowering and laboratory markers during the multidisciplinary treatment. Cancer patients treated with personalized protocols associated with the carotid region reduce the health-disease process related to morbidities as a consequence of the dysgeusias and imbalance of the oral microbiome. Adding to these benefits of photoenteral therapy (ILIB modified), systemic ones, promoted by the bifurcation of the primitive carotid artery in internal and external, triggering a homeostatic hormonal balance and vascularization of the anterior region of the face, correspondingly.
\end{abstract}

Keywords: Leadership; Teamwork; Scenario Awareness; Non-Technical Skills; Standards; Task Performance Analysis; Resurgence; Medical Emergency Team, Beside Author; Journal Searches

\section{Introduction}

The common carotid artery bifurcates to the upper edge of the thyroid cartilage. They are two (right and left) and have different origins: the right carotid artery originates from the brachiocephalic trunk, while the left carotid artery originates from the aortic artery. Each carotid artery divides into two, the internal and external ca rotid arteries (Figure 1) It is the carotids that palpate when we look for the wrists in the neck - and that the rescuers look for to evaluate the cardiac state of the unconscious patient. But what makes the cerebral circulatory system different is the famous Willis polygon. The internal / external arteries join in this circulatory structure at 
the base of the brain and it is from it that virtually all the arteries that irrigate the brain come out. Its main functions are to balance incoming blood pressures in the brain and to create alternative ways for the blood to keep circulating, even if one of the great arteries has a momentary interruption. However, if the pressure drops, the irrigation of the brain is compromised, or any of the great arteries fail, the unconsciousness is quickly generated. Unconsciousness is one of the mechanisms that the brain has to protect itself from poor blood supply, as it leads to imbalance; and being lying down ensures easier blood supply to the brain as well as reduced brain activity and thereby reduces the needs for blood and, of course, for glucose and oxygen. From the polygon of Willis, there are several arteries that penetrate deep into the brain, in both hemispheres, ensuring the formation of cerebrospinal fluid. It is the cerebrospinal fluid that delivers nutrients to the nerve cells in the brain and spinal cord, which means that the system that irrigates the brain is also responsible for nourishing the spinal cord. Another aspect to mention is that the cerebrospinal fluid is a filtrate of blood that reaches the brain, a kind of membrane, which creates the so-called blood-brain barrier, protecting the brain from toxic substances that may circulate in the blood.

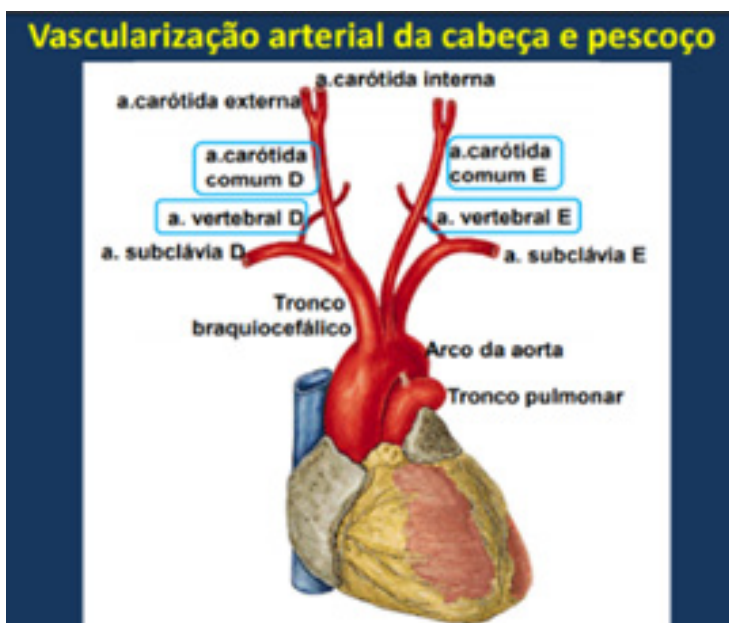

Figure 1: Arterial Vascularization of Head and Neck. Source: Institute of Biomedical Sciences, USP Department of Anatomy Profa. Dr. Gabriela Placoná Diniz.

The internal carotid artery does not emit cervical branches and penetrates the skull through the carotid canal. The posterior part of the brain is irrigated by the vertebral artery (branch of the subclavian artery). The external carotid artery is related to muscles and nerves - sternocleidomastoid, digastric, hyoid-style, hypoglossal nerve, submandibular gland and angle of the mandible [1].

The main branches of the external carotid artery are:

Upper thyroid artery: thyroid gland and larynx;

Lingual artery: muscles of the tongue, floor of the mouth, sublingual gland;

Facial artery suprahyoid muscles, lower and upper lip;
Occipital artery: occipital region, posterior belly of the digastric;

Posterior auricular artery: external ear, parotid gland;

Ascending pharyngeal artery: pharynx;

Surface temporal artery: parotid gland, parotid duct, temporal region, frontal region;

Maxillary artery: dura mater, mastication muscles, teeth, palate.

The external carotid artery supplies most of the soft tissues of the head. It emits collateral branches during its ascending course and at the height of the neck of the jaw it emits its terminal branches.

The external carotid artery emits collateral branches, such as:

Lingual artery: has several ramifications to irrigate the tongue;

Deep artery of the tongue;

Dorsal branches of the tongue;

Sublingual artery;

Supra-hyoid branches;

Facial artery: It is covered only by the skin and the platysma muscle. It is accompanied by the facial vein and the vessels are crossed with the marginal branch of the facial nerve jaw. Because they are very superficial, they can be easily injured directly by trauma and also during incisions, such as those made to drain odontogenic abscesses in this region;

Submental artery;

Ascending palatine artery;

Lower labial artery;

Upper labial artery;

Angular artery;

Maxillary artery: supplies the irrigation of the deep regions of the face, including the upper and lower teeth;

Middle meningeal artery - irrigates the dura mater and trigeminal ganglion;

Lower alveolar artery - dental and peridental branches and milo-hyoid branch;

Mental artery;

Anterior deep temporal artery;

Posterior deep temporal artery;

Masseric artery;

Oral artery;

Posterior superior alveolar artery; 
Infraorbital artery;

Sphenopalatine artery - terminal branch (pterygopalatine fossa);

Major, minor and descending palatine artery - irrigation of the posterior part of the palate;

Superficial Temporal Artery:

Transverse artery of the face;

Front branch;

Parietal branch;

Terminal branches of the external carotid artery involving ATM:

Maxillary artery;

Superficial temporal artery;

Lower alveolar artery.

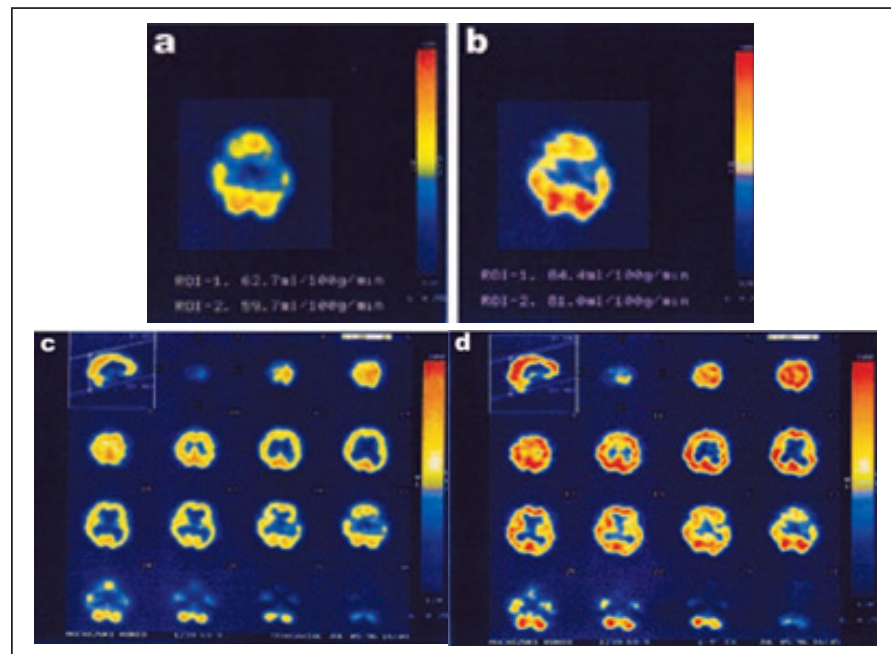

Figure 2: SP (ECT images showing increased cerebral blood flow comparing post-ILIB images with basal, nonirradiated results. (a, b) SPECT transverse magi used to calculate the increase in blood flow in selected regions of interest (ROls see also Table 1) of the brain: ROI 1, right base nuclei; ROI 2, posterior lobe. (c,d) Sagittal image (upper left) and a complete series of cross sections showing increased post-ILIB blood flow.

The biomedical effects of low-power LASER irradiation are evolving in several health areas in a universal way. Some benefits such as immunosuppression-immunostimulation, autoimmune disease and nerve regeneration are evidencing new multidisciplinary nuances $[2,3]$. Basic physiological effects and mechanisms of low-intensity LASER are notorious and redundant in several randomized trials with excellent results in the areas of collagen metabolism, healing, inflammation and pain control (Figure 2). The clinical applications resulting from these studies at a cellular level are generalized and include several therapies that involve the treatment of ligament and tendinous lesions, bursitis, arthritic disease, wound healing, acupuncture, punctual therapy and pain control in general [4]. It should be noted that this functional action of carotid trans- dermal LASER (Figure 3) needs to be accompanied by individualized protocols, type of chemotherapy and / or stage of the chemotherapy cycle, associated medications, capillary glycemia (DM2) the use of a hormone blocker is monitored in the trans-operative by oximetry, since oxyhemoglobin loading allows the measurement of the level of perfusion and control of bradykin in the more peripheral regions of the body [5]. This process of Carotid Irradiation under the criteria of Individualized Medicine (personalized protocols) allowed this hospital unit (Cancer Hospital of Ribeirão Preto / SOBECcan) by photobiomodulation eradicated 641 days ago (as of this date) the cytotoxic injuries of the oropharyngeal region, among such as mucositis, and stabilization of the oral microbiome, which contribute to the reduction of morbidities, an improvement in the emotional state and the overall health of these patients.

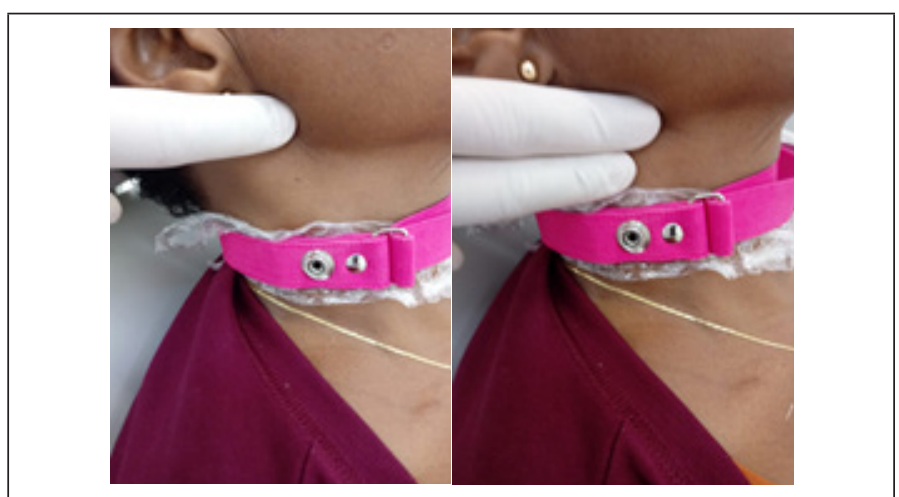

Figure 3: Anatomical location of the primitive carotid artery through the cervical collar provided by Dr. Luciana Rodrigues Chaves Meirelles. Source: Hospital of Cancer of Ribeirão.

Dysgeusia is variably defined as an abnormality harmful to taste sensations, which causes unpleasant alteration of the taste sensation, or a distortion or perversion of the sense of taste. It can be described as bitter, metallic, salty or unpleasant taste. Dysgeusia is closely linked to changes in taste. Flavors provide sensory information related to sensory pleasure and these sensory functions are directly affected by cancer therapies [6]. These changes in taste in patients with cancer are prevalent problems due to the malignancy itself or to the therapeutic interventions that affect the daily quality of life of these patients and may lead to malnutrition, weight loss and, in severe cases, significant morbidity $[7,8]$.

Dysgeusia is clinically evaluated by measuring the detection or recognition threshold values for the five palates: sweet, bitter, acid, salty and umami (the taste of protein-rich foods), either by the application of filters paper impregnated with various concentrations of basic taste) or, in the laboratory environment, with the use of an instrument called elegerígio. These qualitative changes are reported through patient complaints, interviews, and clinical observations [9].

This sensory system in cancer patients is orchestrated by numerous exogenous and endogenous factors that interact with one another. Faced with this, these factors are responsible for abnor- 
malities of taste and odor due to this interconnection. However, such damage to sensory receptor cells is abnormal, but the etiology of these is related to the neuronal activities causing taste and odor abnormalities in these patients. And according to contemporary scientific research, these disorders are probably multifactorial. But it is conclusive by many authors that oncological therapies can cause taste disturbance with the destruction of taste receptors.

And this cellular damage may manifest in three ways:

a) a decrease in the number of normal recipient cells,

b) cell structure change or receptor surface changes, and

c) interruption in neural coding.

Oncoterapeutic agents kill cells with high rates of rotation. Cancer treatment can also affect neuronal activities as well as receptor cells. In addition, hormonal drugs help damage neuronal cells, thereby modifying the afferent pathways that trigger the taste. Recent research has indicated that lipid peroxidation of oral epithelial cells may contribute to the production of carbonyls that cause a metallic taste sensation. Many of these drugs have bitter-tasting compounds that can enter the mouth through the plasma crevicular fluid or may diffuse capillaries to the back of the palate. Finally, the importance of the subject and reflexive noxiousness is that the tamoxifen - anastrozole hormone blockers can compromise the pleasure produced by the taste through the formation of conditioned aversions, which makes this pleasure of feeding, a "nasty" and worrying action.

The Conference on Oral Complications of Cancer Therapies and the publication of the National Cancer Institute have guided the multidisciplinary class to clinical recommendations to minimize the formation of conditioned palatal aversions [10].

It is important to note that since the 1980s there has been a dramatic increase in the number of research involving infection and cancer. The results of such research have made cancer today eminently regarded as a host disease and environmental factors, which together are capable of altering various aspects of cellular metabolism by making the affected cells more competitive in terms of rate of replication, reduction of apoptosis, resistance to therapies, and with greater invasiveness and colonization. However, several articles have shown that infectious agents should play a central role in about $20 \%$ of neoplasias [11,12], which is based on types of cancer with known infectious etiology such as cervical, hepatic and gastric cancer [11]. There are sites in the human body, including the entire aerodigestive tract, where the contact with the external environment is greater, making the direct role that the microbiome has on these more prominent sites. Among these body regions, the intestine and the "oral cavity" have the highest and second highest microbial diversity, suggesting that the study of the relationship between these microorganisms and other regions of the body may contribute to the greater knowledge about their relationship caus- al or not) with the development of diseases caused by infectious agents, including cancer [13]. The installation of dysgeusia in the oral cavity allows the patient a physiological decrease in the immune system, which corrupts the rest of the stomatognathic system, through the potentiation of the microbioma that plays a key role in metabolism, inflammation and immunity. contribute to carcinogenesis. To date, there are some hypotheses for bacterial-mediated carcinogenesis mechanisms, such as the activation of Toll-like receptors, bacterially derived genotoxins, bacterial virulence factors, and carcinogenesis affected by microbial metabolism [14]. While the microorganisms present in the various mucous membranes of the body can become part of the tumor microenvironment, other microorganisms can invade the cells, becoming intratumoral, resulting in tumor growth through different pathways [15].

Alternatively, the "oral microbiome" initiates the breakdown of dietary elements and produces pro-carcinogenic agents [16]. In a recent analysis of microorganisms found in the mucosa oral healthy, a large number of microorganisms capable of producing high amounts of acetaldehyde from ethanol [16] have been demonstrated, a fact of concern regarding the carcinogenic properties of acetaldehyde, as well as the positive association between alcohol and certain types of cancer.

Thus, it is now recognized that the microbiota contributes to carcinogenesis in three broad ways:

a. Altering the balance between death and proliferation of host cells;

b. acting on the balance of the immune system; and

c. Influencing the metabolism of several substances, being able to generate pro - or anti - tumor substances [17].

Hence the importance of the balance of oral cavity functionalities for the stabilization or regression of carcinogenic conditions. According to the latest data from INCA (National Cancer Institute - Brazil), 40.5\% of patients on oncological therapies present dysgeusia and the proposed conventional treatments refer to the nutritional orientation:

a. To make the patient aware of the need to eat, despite dysgeusia and dysosmia;

b. Encourage more pleasurable food intake;

c. Increase diet fractionation and reduce volume per meal, providing 6 to 8 meals a day;

d. Modify the consistency of food as acceptance, blending it when necessary;

e. When necessary, use nutritional supplements with flavorings and aromas;

Guide the patient to: 
a) Prepare visually pleasing and colorful dishes;

b) Remember the taste of food before eating them;

c) Give preference to foods with stronger flavors;

d) Use herbs and condiments in the preparations, obtaining significant results in the medium and long term.

However, as regards the alteration of the oral microbiome, the involvement may reach $76 \%$ of the patients submitted to oncoterapias, and the global literature proposes the use of chlorhexidine-based mouthwash at $0.12 \%$ to maintain the balance of the flora. I would add that according to data from the Brazilian Hospital Nutrition Evaluation Survey (Ibranutri), it was found that the malnutrition rate in cancer patients is almost three times higher than that of other hospitalized patients, reaching $66.3 \%$ against $42.9 \%$, and the global incidence is estimated at $85 \%$, and much of this lack of appetite is due to the alterations of the oral microbioma and dysgeusia leading patients to a decrease in general health that may lead to death. And, according to the epidemiological sense of the Ministry of Health (2015), 54.2\% of patients abandon the conventional treatments proposed above, negatively impacting the cure rate of the disease. In contrast, the proposal to study this new protocol of photobiomodulation constitutes a topical, non-invasive, low-cost, non-side-effect, which may provide a short / medium term response to sensory responses of the taste buds and regularization of flora buccal, impacting the multidisciplinary therapies proposed in oncology.

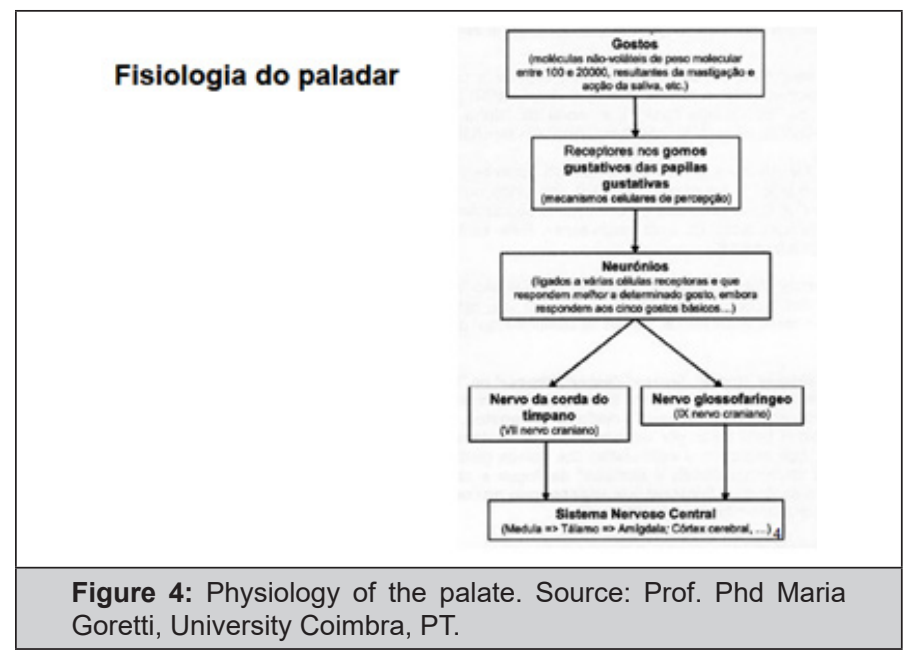

The hormones used in this Hospital, as a reference to "Breast Cancer", impact on changes in the taste of food and change in oral flora leading these patients to reduce interest in food, which leads to decreased intake, resulting in nutritional deficit and weight loss. I reiterate that countless studies report on the side effects of hormone therapy and that high index of patients presents complaints of changes in taste. This is because the cytostatic agents are secreted in the saliva or they can diffuse in the plasma into the oral cavity, besides the Central Nervous System (Figure 4) that promotes the maintenance of the stimuli of the palate by contacting directly with taste receptors. An important etiology seems to be the inhibitory effect of the agent's cytostatic effects on receptor cell mitosis, since in many patients, changes in taste resolve late when cell turnover is restored. Studies suggest that these drugs initially mentioned are associated with sensory alterations of the palate, however, comparative studies between the different agents and their impact on the alterations are scarce. Dysgeusia may persist after elimination of the drug by injury to the taste buds. While some studies show that changes in taste can start right after the start of treatment others show that they can start within ten weeks. During the cycles of these drugs the duration of this dysfunction can be from hours to weeks. And post-term chemotherapy and hormone-onset alteration may last up to a year, but there are cases "in this hospital" detected by the oncology dentistry department of patients who were 4 years old under dysgeusia dysfunction.

It should be reiterated that the preponderant function in these target protocols is to minimize this cytotoxic effect caused by these drugs against the side effects caused in the oral cavity through the low-cost and non-invasive photobiomodulator system, avoiding the imbalance of the buccal flora and destabilization of the sensory function of the palate.

\section{Discussion}

The increase in carotid artery flow after a Low Intensity Lasertherapy session was detected after irradiation on one side of the neck in 12 human patients, with increased blood flow on the irradiated side (63\%) and increased cross-sectional diameter of the external carotid artery (69\%) as objectively evaluated with color Doppler flowmetry [18]. Interestingly, on the non-irradiated side, blood flow and transverse volume (71\% and 52\%, respectively) were also observed, so that the blood flow on the non-irradiated side actually increased to a greater extent than on the irradiated side. These changes persisted for more than an hour before they began to fall back to the basic readings. Single photon emission tomography (SPECT) is a diagnostic technique by which a tracer of radioactive isotopes, the radionuclide, is injected into the individual. A camera-based scanner captures three-dimensional real-time tracer images in the cerebral arteries, and a computer image is then able to describe changes in 3-D or 2-D cerebral blood flow in any airplane.

Shows SPECT images compared between the onset and after a Low Intensity LASER session in the same patient (Figure 2) Increased cerebral blood flow was clearly visible throughout the brain after ILIB, both in the transverse (Figure 2a \& Figure 2b) and sagittal (Figure 2c \& 2d) planes. Table 1 shows the computer-calculated rate of increase of blood flow in two regions of interest (ROIs) of the brain compared between baseline and post-ILIB images.

This radiation emitted by Low Power LASERS (LBP) has demonstrated analgesic, anti-inflammatory and healing effects and is therefore widely used in the tissue repair process due to the low 
energy densities used and wavelengths capable of penetrating in tissues [19]. Photobiomodulatory therapy performed at the Hospital of Cancer of Ribeirão Preto (16 female patients, resulting from Cancer, primary site of breast), the use of the cervical collar (anatomical positioner) in the primitive carotid artery was used for the application of transdermal phototherapy low-intensity (ILIB modified), red irradiance, EC device (DMC), net power emitting red LASER: $100 \mathrm{~mW} \pm 20 \%$, red LASER wavelength $660 \mathrm{~nm} \pm 10$ $\mathrm{nm}$, continuous flow of 10 minutes which equals 60 JOULES total per session, periodicity of $1 \mathrm{x}$ per week, from October 2018 to April 2019, which produced significant data collections to the primary / biochemical (Table 2) and secondary / clinical effects (Table 3).

Table 1: Rate of cerebral blood flow increase in selected regions of interest (ROI) at baseline and after ILIB, as monitored by SPECT.

\begin{tabular}{|c|c|c|c|c|}
\hline \multirow{2}{*}{ Regiào de interesse } & \multirow[t]{2}{*}{ Localizaçào } & \multicolumn{2}{|c|}{ Fluxo sanguineo } & \multirow{2}{*}{ Taxa de aumento } \\
\hline & & Linha de base & Post PPLT & \\
\hline ROI 1 & Nücleos basais direitos & $62,7 \mathrm{ml} / 100 \mathrm{~g} / \mathrm{min}$ & $84,4 \mathrm{ml} / 100 \mathrm{~g} / \mathrm{min}$ & $36 \%$ \\
\hline ROI2 & Lobo posterior & $59,7 \mathrm{ml} / 100 \mathrm{~g} / \mathrm{min}$ & $81,0 \mathrm{ml} / 100 \mathrm{~g} / \mathrm{min}$ & $35 \%$ \\
\hline
\end{tabular}

Table 2: Reference values of the markers in the range

*TGO 5 to $40 \mathrm{u} /$ I URÉIA 15 to $45 \mathrm{mg}$ / dl PLATELETS 150,000 to $350,000 \mathrm{mmm}^{3}$

*TGP 7 to $56 \mathrm{u} /$ I NEUTROPHIL 1600 to $8000 \mathrm{mmm}^{3}$ CA 15-3

The primary (biochemical) effects observed were better when applied to cervical ILIB therapy.

ILIB MOD. Patients: Intravascular Laser Irradiation of Blood transdermic in the primitive carotid artery.

\begin{tabular}{|c|c|c|c|c|c|c|c|}
\hline $\begin{array}{c}\text { Therapy } \\
\text { primary efiects } \\
\text { momen }\end{array}$ & $\begin{array}{l}\text { LIB } \\
\text { MOD. } \\
\text { Patients }\end{array}$ & $\begin{array}{c}\mathrm{TGO} \\
\mathbf{m}\end{array}$ & $\begin{array}{c}\text { TGP } \\
w 1\end{array}$ & $\begin{array}{l}\text { UREIA } \\
\text { mg/dil }\end{array}$ & $\begin{array}{c}\text { NEOTROPRFIL } \\
\text { mmms }^{3}\end{array}$ & $\begin{array}{l}\text { PLATELETS } \\
\text { mmm }^{3}\end{array}$ & $\begin{array}{l}\mathrm{CA} \\
15.3\end{array}$ \\
\hline TAMOXIFENO & 06 & 28,1 & 31,23 & 37,38 & 3.200 & 234.000 & 27,40 \\
\hline ANASTROZOL & 06 & 18,84 & 17,98 & 32,58 & 2.775 & 269.000 & 43,82 \\
\hline NOMIEDICATIONS & 05 & 14,46 & 12,83 & 33,45 & 3.035 & 243.000 & 39,40 \\
\hline VARIATIONS & - & 20,47 & 20,68 & 34,47 & 3.003 & 248.000 & 36,87 \\
\hline
\end{tabular}

Currently, this Low Intensity LASER (LBI) is being used for the overall recovery of the patient in several specialties of the health area; and their responses are considered to be beneficial $[20,21]$ in a variety of different modalities, due to their multifactorial effect [22]. Specifically, this mechanism when triggered in the craniofacial region is related to "neuronal repair and in neurogenesis, "not only in the formation of new brain cells but also in" synaptogenesis, "which is the formation of new connections between existing brain cells.

Therefore, the systemic and localized conditions during cancer treatment therapy contribute to the reduction of sensory capacity of the palate, causing transient or definitive dysgeusias, and in this niche of patients who use chemotherapeutic drugs and hormone-blockers these functions are altered often with a negative influence on organic and emotional well-being.

However, when it acts at the cellular level, low power LASER causes biochemical, bioelectric and bioenergetic modifications, influencing the increase of metabolism, cell proliferation and mat- uration, the amount of granulation tissue and the decrease of inflammatory mediators, stimulation of Neural checkpoints induce the production of hormones produced by neural endorphins - dopamine - serotonin - oxytocin, and the healing process [23,24]. And when the molecule is absorbed by light, it allows an increase in cellular metabolism, characterized by stimulation of photoreceptors in the mitochondrial respiratory chain, alterations in cellular ATP levels, release of growth factors and collagen synthesis [25].

Table 3: Systemic infections caused by oral microorganisms Lotufo RFM, Pannuti CM - 2004.

\begin{tabular}{|c|c|}
\hline \multirow{4}{*}{ Infective Endocarditis } & Estreptococos bucais \\
\hline & E. corrodens \\
\hline & A. actinomycetemcomitans \\
\hline & M. micros \\
\hline \multirow{4}{*}{ Bacteremia } & Estreptococos bucais \\
\hline & P. gingivalis \\
\hline & Enterobacteriaceae \\
\hline & Cândida sp. \\
\hline Sepsis & A. actinomycetemcomitans \\
\hline Brain abscess & A. actinomycetemcomitans \\
\hline \multirow{3}{*}{ Respiratory infections } & A. actinomycetemcomitans \\
\hline & Enterobacteriaceae \\
\hline & Staphylococcos \\
\hline Oftalmoplegia & A. actinomycetemcomitans \\
\hline Intra-abdominal infections & P. gingivalis \\
\hline Otitis media suppurative & P. gingivalis \\
\hline Vaginal infections & M. micros \\
\hline Chronic conjunctivitis & M. micros \\
\hline Endoftalmite & A. actinomycetemcomitans \\
\hline Ovarian tube abscess & P. gingivalis \\
\hline
\end{tabular}

This ILIB adjuvant function triggers an antioxidant system composed of enzymes, the main metallo-enzyme superoxide dismutase, or SOD $\mathrm{ZnCu}$, is the largest antioxidant [26] we have and fifth volume enzyme in the human body. However, according to a recent review, evidence suggests that the enzymes catalaseperoxidase and ceruloplasmin also absorb red LASER which potentiates other enzymes, which obviously further increases the antioxidant property of these enzymes when irradiated in the ILIB process. Therefore, these therapeutic effects of light elucidate elucidate the side effects caused by the chemotherapeutic and hormone therapy cycles.

In the last three years, the oncological dentistry department of the Ribeirão Preto Cancer Hospital has investigated issues related to the use of low intensity LASER (photobiomodulation) for the recovery of dysgeusia that cause a relevant impact on the control of the oral microbiome, reflecting the reductions in xerostomia, hyposalivation, viral-fungal-bacterial infections and gradual return of palatal function that contribute in a timely manner to the reduction of the development of diseases associated with oncological treatments. Note that the authors (Table 3) identified a number of path- 
ogens related to systemic diseases [27], showing the diversity of the oral microbial, opening space for colonization by microorganisms in other organs that in an analogical way may have an impact on the effect of carcinogenesis by producing carcinogenic agents potent Studies have recently revealed that the oral microbiome in cancer patients have a bacterial sensitivity and specificity above 90\% [28].

Adjuvant functions of the LASER trigger an antioxidant system composed of enzymes, the main metallo-enzyme superoxide dismutase, or SOD $\mathrm{ZnCu}$ is the largest antioxidant [26] we have and fifth volume enzyme in the human body. However, according to a recent review, evidence is enzymes catalase peroxidase and ceruloplasmin also absorb red LASER which potentiates other enzymes, which obviously further potentiates the antioxidant properties of these enzymes when irradiated in this process [29]. These therapeutic effects of light can minimize the side effects caused by oncoterapies and the importance of the topic related to dysgeusia and its systemic reflexes from the microbioma of the oral cavity, it is interesting to elucidate that the main attention of the patients is the healthy longevity, which treated preventively or at other stages of the disease establishment, will have a considerable quality of life, as well as promote carcinogenic reduction of the tumor (any organs), balance of the microbiota, reduction of free radicals and increase of the blood supply in the craniofacial region.

The researches of the Photobiomodulation and the microbioma of human cancer appear as areas of extremely relevant and current research, within a multiprofessional context and reduction of morbidities.

\section{Conclusion}

Both subjective evaluation of objective tests, there is clearly an increase in local cerebral and systemic blood flow after ILIB carotid procedures (cervical collar) with pain relief (Behavioral Scale pain Rancho Los Amigos), improvement of biomarkers (blood count complete with platelets, Ca15-3), balance of the oral microbiome, reduction of dysgeusia (universal palate scale), control of arthralgias in the first months (Graph 1) and sensation of well-being. Besides oropharyngeal balance this therapy enabled patients with lower liver risk control transaminase (SGOT / SGPT), and other systemic complications buoyed by urea, neutrophils and platelets that remained at a good level. CA15-3 remained at low levels reducing the possibility of cancer recurrence. The group that did not receive the hormonal medication had a good response, and the groups that underwent hormonal therapy (Table 2) obtained results that were lower but relevant for reducing morbidities. The increase of the parasympathetic control is one of the main reasons suggested and would tend to be verified by the objective thermography, the Doppler flow meter and the SPECT evaluation (Figure 2). In addition to the verification of imaging findings in world literature, it should be reaffirmed that efficacy is demonstrated in the clinical / laboratory responses, in the pre-trans-post stages of cervical LASER applica- tions and control groups during the last 2 years of protocols transdermal arteries in the region of the primitive cervical carotid artery mentioned in the text, causing promising impacts in this universe and expressive suspension of many intercurrences. The biological restoring these individuals in laser therapy and consequently returning to social life is mediated by clinical and laboratory functions through continuous monitoring of biomarkers, primary and secondary effects triggering a collective welfare in the harvest cancers.

\section{References}

1. Gabriela Placoná Diniz (2018) Vascularização arterial da cabeça e pescoço Instituto de Ciências Biomédicas da USP.

2. Karu T (1998) The Science of Low Power Laser Therapy. Gordon and Breach, London.

3. Cleber Ferraresi, Fernanda Freire, Michael R (2018) Hamblin Photobiomodulation in Bone: Studies in vitro, in vivo, and Clinical Applications pp. 169-182.

4. Chavantes MA (2009) Laser em Bio-Medicina Princípios e Prática.

5. Demchak (2014) Associate Professor at Indiana State University in the Department of Applied Medicine and Rehabilitation.

6. Heckmann SM, Hujoel P, Habiger S, Friess W, Wichmann M, et al. (2005) Zinc gluconate in the treatment of dysgeusia-a randomized clinical trial. J Dent Res 84(1): 35-38.

7. Halyard M (2009) Alterações de sabor e cheiro em pacientes com câncer - problemas reais com poucas soluções. J Suporte Oncol p.7.

8. Steinback S (2009) Avaliação qualitativa e quantitativa de mudanças de sabor e cheiro em pacientes submetidos a quimioterapia para câncer de mama ou doenças malignas ginecológicas. J Clin Oncol p. 27.

9. Hong JH (2009) Anormalidades de sabor e odor no câncer pacientes. J Suporte Oncol 7(2).

10. Bartoshuk LM (1990) Alterações quimiosensivas e câncer terapias. NCl Monogr p.9.

11. Parkin DM (2006) The global health burden of infection -associated cancers in the year 2002. Int J Cancer 2006.

12. Martel C, Ferlay J, Franceschi S, Vignat J, Bray F, et al. (2012) Global burden of cancers attributable to infections in 2008: A review and synthetic analysis. Lancet Oncol 13(6): 607-615.

13. Lazarevic V, Whiteson K, Hernandez D, François P, Schrenzel J (2010) Study of inter- and intra-individual variations in the salivary microbiota. BMC Genomics.

14. Schwabe RF, Jobin C (2013) The microbiome and cancer. Nat Rev Cancer 13(11): 800-812.

15. Elinav E, Nowarski R, Thaiss CA, Hu B, Jin C, et al. (2013) Inflammation-induced cancer: Crosstalk between tumours, immune cells and microorganisms. Nat Rev Cancer pp. 759-771.

16. Moritani K, Takeshita T, Shibata Y, Ninomiya T, Kiyohara Y, et al. (2015) Acetaldehyde production by major oral microbes. Oral Dis 21(6): 748754.

17. Garret WS (2015) Cancer and the microbiota. Science 348: 80-86.

18. Monobe H, K Miyano, Kagoya R, Tojima H 02012) Case of progressive facial hemiatrophy with cervical sympathetic hyperactivity as underlying aetiology. J Laryngol Otol 126(7): 725-728.

19. Lapchak PA, Boitano PD, Butte PV, Fisher DJ, Holscher T, et al. (2015) Rajput PS Perfis Transcranianos de transmissão por laser infravermelho próximo (NILT) (800 nm): comparação sistemática em quatro comuns Pesquisar espécies. PLoS One 
20. Sindi SCE, Fokkens J, Ngandu T, Soininen H, Tuomilehto J, et al. (2014) The CAIDE Dementia Risk Score App: The development of an evidence-based mobile application to predict dementia. 13th Internationa Geneva/Springfield Symposium on Advances in Alzheimer Therapy, Geneva, Switzerland.

21. Bellou V, Belbasis L, Tzoulaki I, Evangelou E, Ioannidis JP (2016) Environmental risk factors and Parkinson's disease: An umbrella review of meta-analyses. Parkinsonism Relat Disord 23: 1-9.

22. Kaplan GB, Vasterling JJ, Vedak PC, Behav Pharmacol (2010) Brain-derived neurotrophic factor in traumatic brain injury, post-traumatic stress disorder, and their comorbid conditions: role in pathogenesis and treatment. Behav Pharmacol 21(5-6): 427-437.

23. Silva EM, Gomes SP, Ulbrich LM, Giovanini AF (2007) Histological evaluation of the effects of LLLT on the epithelial, connective and osseous tissue healing: experimental study in rats. Rev Sul-Bras Odontol.

24. Bourguignon AMF, Feitosa RCA, Beltrão GC, Pagnoncelli MR (2005) Utilização do laser de baixa intensidade no processo de cicatrização tecidual. Revisão de literatura. Rev Port Estomatol Cir Maxilofac 46: 37-43.
25. Basso FG, Oliveira CF, Kurachi C, Hebling J, Costa CA de S (2013) Biostimulatory effect of low-level laser therapy on keratinocytes in vitro. Lasers in Medical Science 28(2): 367-374;

26. SILVÉRIO L Sandra (2013) Faculdade de Tecnologia IBRATE, Analgesia por Acupuntura, Omnipax Editora.

27. RFM lotufo (2004) CM Pannuti-Brunetti MC-Periodontia Médica. São Paulo: SENAC, Brazil.

28. Thomas AM, Gleber-Netto FO, Fernandes G, Amorim MG, Barbosa LF, et al. (2014) Alcohol and tobacco consumption affects bacterial richness in oral cavity mucosa biofilms. BMC Microbiology 14: 250.

29. Pacheco JA, Bezinelli LM (2018) The Photobiomodulatory Therapy and ILIB in the Repair of ncephalic Cisterns and Progressive Cognitive Restoration in a Patient with Traumatic Brain Injury. Med Case Rep 4(2): 73. 